\title{
Resistência à erosão de concretos refratários de alta alumina nanoligados
}

\section{(Erosion resistance of nanobonded high-alumina refractory castables)}

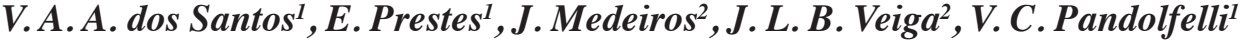 \\ Departamento de Engenharia de Materiais - Universidade Federal de S. Carlos \\ Rod. Washington Luiz, Km 235, C. P. 676, S. Carlos, SP 13565-905 \\ ${ }^{2}$ Petrobras - CENPES/EB-AB-G\&E/EEQ - Rio de Janeiro, RJ \\ epres@uol.com.br,vicpando@power.ufscar.br
}

\begin{abstract}
Resumo
A avaliação do emprego de concretos refratários nanoligados em aplicações onde ocorre desgaste por erosão é de importante interesse devido aos estudos recentes que indicam esta rota como uma alternativa à substituição do cimento de aluminato de cálcio. Neste trabalho, os resultados de resistência à erosão a frio de formulações de concretos refratários de alta alumina ligados por sílica coloidal e a combinação deste aditivo com alumina hidratável, foram comparadas a um concreto refratário aluminoso de uso comercial, ligado por cimento de aluminato de cálcio, especificado pelo fabricante para uso em aplicações de desgaste por erosão. Os resultados mostraram um desempenho superior dos concretos nanoligados, indicando que a utilização deste agente ligante é muito promissora no desenvolvimento de produtos onde se requer alta resistência ao desgaste por erosão. A razão entre o valor do módulo de ruptura a quente e o volume erodido também se mostrou relevante como técnica de seleção de refratários para tais aplicações.
\end{abstract}

Palavras-chave: concretos refratários nanoligados, sílica coloidal, resistência a erosão.

Abstract

Nanobonded refractory castables for erosion wear applications is of important interest based on recent publications that suggest the use of this route as an alternative to substitute the calcium aluminate cements. In this work, the cold erosion resistance of highalumina refractory castables containing colloidal silica and a blend of colloidal silica and hydratable alumina as bonding agents were comparated to commercial calcium aluminate cement containing alumina refractory castable, specified by the producer as a suitable material for erosion wear applications. The results showed higher performance for the colloidal silica bonded castables, suggesting the use of this bonding system in the development of refractory castables for erosion wear applications. The ratio between the hot modulus of rupture and the eroded volume has also been shown as a relevant technique for the refractories selection in such environments.

Keywords: nanobonded refractory castables, colloidal silica, erosion resistance.

\section{INTRODUÇÃO}

Estudos recentes sugerem o emprego da sílica coloidal como uma promissora alternativa à substituição do cimento de aluminato de cálcio como sistema ligante em concretos refratários [1-7]. O desenvolvimento da resistência mecânica nestes sistemas, diferentemente dos cimentos aluminosos onde ocorre a formação de hidratos, deve-se a condensação de grupos silanol $(\mathrm{Si}-\mathrm{OH})$ presentes na superfície das partículas que reagem entre si. Este processo denominado de gelificação do sol resulta em uma ligação silano (-Si-O-Si-) que une duas partículas e as torna hidrofóbicas. Novas partículas se unem a esse aglomerado e uma rede tridimensional é formada [8]. Como não há ligações químicas com a água, esta pode ser eliminada rapidamente e os riscos de explosões e trincamentos são atenuados. Adicionalmente, também proporciona maior facilidade de mistura e menor susceptibilidade às condições de cura em relação ao cimento de aluminato de cálcio e a sua elevada pureza contribui para o aumento da refratariedade da maior parte dos sistemas aluminosos e sílico-aluminosos [2]. Uma outra possibilidade de uso de agentes ligantes alternativos é a combinação de sílica coloidal e alumina hidratável, o que gera sistemas com reduzida porosidade e elevados valores de resistência mecânica a verde [5] Um aspecto importante da sílica coloidal é que devido ao tamanho nanométrico de suas partículas, a elevada área superficial resultante, aumenta a reatividade do sistema e proporciona um considerável progresso no desenvolvimento de resistência mecânica com o aumento da temperatura de queima [9-10]. Considerando que este efeito esteja relacionado a uma maior força de ligação entre as partículas da matriz do concreto refratário, proporcionada pela elevada sinterabilidade do sistema, é provável que a resistência à erosão também seja melhorada pela utilização da sílica coloidal como agente ligante. Sendo a matriz que mantém os agregados unidos, ela apresenta um importante papel no desgaste por erosão. Observações mostram que 
quando ela é erodida, os agregados ficam desprotegidos e se desprendem da superfície do refratário [11].

Nas aplicações onde o revestimento está sujeito ao desgaste por erosão, o uso de materiais de superior desempenho é de fundamental importância para a redução dos custos de manutenção e o risco de paradas não planejadas. Devido a isto, torna-se necessário a realização de trabalhos para avaliação da aplicação dos sistemas ligados por sílica coloidal em linhas de transferência de hidróxido de alumínio em calcinadores de leito fluidizado e no transporte de catalisadores da indústria petroquímica [12].

Neste sentido, este trabalho destaca os resultados de resistência à erosão a frio de concretos refratários de alta alumina contendo sílica coloidal e alumina hidratável como agentes ligantes. A pesquisa serve como uma avaliação preliminar do potencial de emprego destes agentes ligantes em concretos refratários submetidos a solicitações de desgaste por erosão.

\section{MATERIAIS E MÉTODOS}

Quatro formulações de concretos refratários, duas contendo somente sílica coloidal (SC) como agente ligante e duas outras contendo uma combinação entre sílica coloidal e alumina hidratável $(\mathrm{SC}+\mathrm{AH})$, foram projetadas a partir do modelo de empacotamento de partículas de Andreasen [13], com coeficiente (q) 0,21 e diâmetro máximo de partícula igual a $4750 \mu \mathrm{m}$. A Tabela I apresenta as matérias-primas e as características gerais da formulação de cada sistema.

Para todos os sistemas um dispersante ácido e um agente coagulante básico foram usados no processamento. Um concreto refratário aluminoso de pega hidráulica de uso comercial, especificado pelo fabricante para emprego em solicitações de desgaste por erosão, também foi avaliado para comparação e para servir como uma referência na análise dos resultados. A Tabela II apresenta as principais características do produto comercial, sendo que, a porcentagem de água adicionada $(6,0 \%$-p) e o procedimento de mistura seguiram as especificações da ficha técnica do produto.

$\mathrm{O}$ processo de mistura dos materiais foi realizado em um reômetro desenvolvido para concretos refratários [14]. Após esta etapa, foram moldados corpos de prova de 115 x 115 x $25 \mathrm{~mm}^{3}$, para realização do ensaio de resistência à erosão a frio, e corpos de prova de $25 \times 25 \times 125 \mathrm{~mm}^{3}$, para determinação do módulo de ruptura a quente. A cura foi realizada a $50{ }^{\circ} \mathrm{C}$ por $24 \mathrm{~h}$ em ambiente insaturado (ao ar). Em seguida, os corpos de prova foram desmoldados e secos em estufa a $110{ }^{\circ} \mathrm{C}$ por um período de $24 \mathrm{~h}$. A queima dos corpos de prova foi realizada a uma taxa de aquecimento de $3{ }^{\circ} \mathrm{C} / \mathrm{min}$, com patamar de $10 \mathrm{~h}$ nas seguintes temperaturas: $600,800,1000,1200,1350$ e $1500{ }^{\circ} \mathrm{C}$. Posteriormente, a face de teste dos corpos de prova para o ensaio de resistência à erosão foi retificada a úmido, seguida por secagem a $110{ }^{\circ} \mathrm{C}$ por $24 \mathrm{~h}$.

A resistência à erosão a frio foi determinada seguindo o procedimento descrito na norma NBR 13185. A perda de material por erosão $\left(\mathrm{cm}^{3}\right)$ foi calculada por meio da equação A:

$$
\Delta V=\left(m_{1}-m_{2}\right) / \text { M.e.a }
$$

onde $m_{1}$ é a massa do corpo de prova antes do ensaio (g), $m_{2}$ é a massa do corpo de prova após o ensaio (g) e M.e.a é a massa específica aparente do corpo de prova $\left(\mathrm{g} / \mathrm{cm}^{3}\right)$. Ensaios para avaliação da resistência mecânica a frio dos concretos (amostras cilíndricas: $\mathrm{d}=\mathrm{h}=40 \mathrm{~mm}$ ) foram realizados para as diferentes temperaturas de queima, utilizando a técnica de compressão diametral (norma ASTM

Tabela I - Matérias-primas e formulação dos concretos refratários.

[Table I - Refractory castables formulation and raw materials.]

\begin{tabular}{|c|c|c|c|c|c|}
\hline & \multirow{2}{*}{ Matérias - primas } & \multicolumn{4}{|c|}{ Denominação } \\
\hline & & $8,7 \% \mathrm{SC}$ & $7,5 \% \mathrm{SC}$ & $5,0 \% \mathrm{SC}$ & $5,0 \% \mathrm{SC}$ \\
\hline $\begin{array}{l}\text { Agregado } \\
(\%-p)\end{array}$ & $\begin{array}{c}\text { Aluminas eletrofundidas marrons } \\
\text { MR 4-200F } \\
\text { (Elfusa - Brasil) }\end{array}$ & 73 & 73 & 77 & 77 \\
\hline $\begin{array}{l}\text { Matriz } \\
(\%-p)\end{array}$ & $\begin{array}{l}\frac{\text { Aluminas calcinadas }}{\text { CL370C, A1000SG }} \\
\quad \text { (Alcoa E.U.A.) }\end{array}$ & 27 & 27 & 18 & 20 \\
\hline \multirow[t]{2}{*}{ Ligante (\%-p) } & $\begin{array}{l}\text { Sílica coloidal } \\
\left.\text { 00BZL021 (40\%-p } \mathrm{SiO}_{2}\right) \\
(\text { Nalco })\end{array}$ & 8,7 & 7,5 & 5,0 & 5,0 \\
\hline & $\frac{\text { Alumina hidratável }}{\text { (Alphabond } 300 \text { - Almatis) }}$ & - & - & 5,0 & 3,0 \\
\hline Teor de água (\%-p) & & 5,8 & 5,0 & 5,0 & 5,0 \\
\hline
\end{tabular}


Tabela II - Características do concreto refratário aluminoso de uso comercial.

[Table II - Characteristics of the commercial refractory castables.]

\begin{tabular}{ccc}
\hline Propriedades & \multicolumn{2}{c}{ Especificação } \\
\hline & $\mathrm{Al}_{2} \mathrm{O}_{3}$ & 62 (mín.) \\
Composição & $\mathrm{SiO}_{2}$ & 35 (máx.) \\
química (\%) & $\mathrm{TiO}_{2}$ & 2,0 (máx.) \\
& $\mathrm{Fe}_{2} \mathrm{O}_{3}$ & 1,5 (máx.) \\
\hline Densidade & $110{ }^{\circ} \mathrm{C}$ x $24 \mathrm{~h}$ & 2,50 \\
aparente $\left(\mathrm{g} / \mathrm{cm}^{3}\right)$ & $1200{ }^{\circ} \mathrm{C}$ x $5 \mathrm{~h}$ & 2,55 \\
\hline Resistência à compressão & $110{ }^{\circ} \mathrm{C}$ x $24 \mathrm{~h}$ & 30 (mín.) \\
a temperatura ambiente & $1200{ }^{\circ} \mathrm{C}$ x $5 \mathrm{~h}$ & 40 (mín.) \\
$(\mathrm{MPa})$ & & \\
\hline
\end{tabular}

C 496-90). As amostras foram ensaiadas em uma máquina universal de ensaios MTS 810, com taxa de aplicação de carga constante de $42 \mathrm{~N} / \mathrm{s}$. A equação B apresenta a fórmula para o cálculo da tensão de ruptura $\sigma_{F}$.

$$
\sigma_{F}=2 . P_{\text {máx }} /(\pi . l . d)
$$

onde $P_{\text {máx. }}$ é a força de ruptura $(\mathrm{N}), l$ e $d$ são a altura e o diâmetro do corpo de prova $(\mathrm{m})$, respectivamente.

Para o ensaio de determinação do módulo de ruptura a quente $(\mathrm{MPa})$ foi empregada uma máquina de flexão a três pontos Netzsch HBST 422. A velocidade de carregamento foi $12,5 \mathrm{~N} / \mathrm{s}$ de acordo com a norma ASTM C 583-8. O cálculo do módulo de ruptura $\sigma_{F}$ foi efetuado segundo a equação $\mathrm{C}$ :

$$
\sigma_{F}=3 / 2 . P_{\text {máx }} \cdot L /\left(b \cdot h^{2}\right)
$$

onde $P_{\text {máx. }}$ é a força de ruptura $(\mathrm{N}), L$ a distância entre os apoios $(0,125 \mathrm{~m}), b$ e $h$ são a largura e a altura do corpo de prova $(\mathrm{m})$, respectivamente. Valores de porosidade aparente também foram determinados utilizando-se o método de imersão de Archimedes (norma ASTM C 830-88).

\section{RESULTADOS E DISCUSSÃO}

\section{Comparação entre os diferentes agentes ligantes}

As Figs. 1 e 2 apresentam os resultados de resistência à erosão a frio dos concretos refratários contendo sílica coloidal e a combinação entre sílica coloidal e alumina hidratável como agente ligante, respectivamente.

A Fig. 1 mostra que para todas as temperaturas de queima os sistemas ligados por sílica coloidal apresentaram resultados inferiores de volume erodido em comparação ao produto comercial. Verifica-se que a porcentagem de ligante influenciou o desempenho, sendo que, os melhores resultados foram obtidos para a formulação contendo $7,5 \%$ em peso. Para a formulação contendo $8,7 \%$ em peso têm-se um

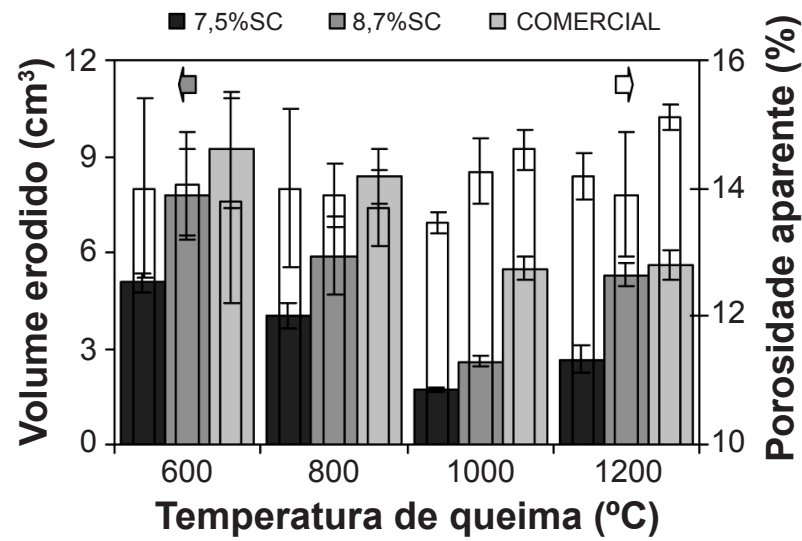

Figura 1: Resistência à erosão dos concretos refratários ligados por sílica coloidal.

[Figure 1: Erosion loss of colloidal silica bonded refractory castables.]

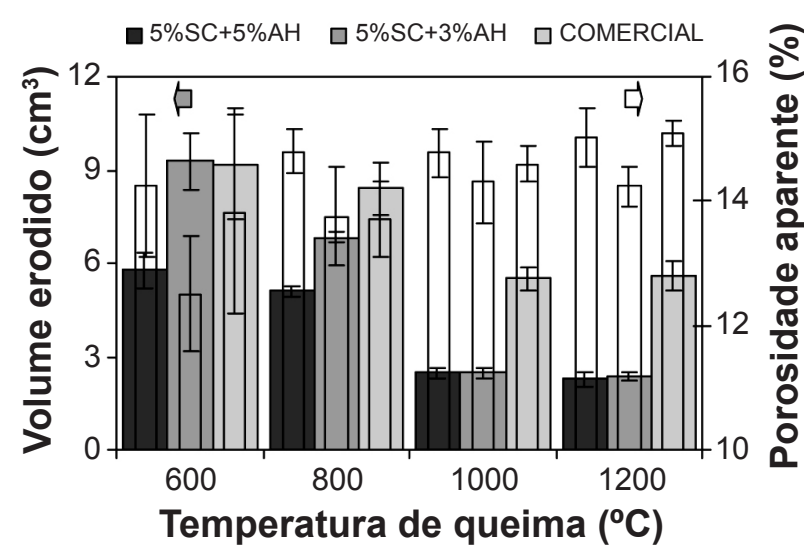

Figura 2: Resistência à erosão dos concretos refratários ligados por sílica coloidal e alumina hidratável.

[Figure 2: Erosion loss of colloidal silica and hydratable alumina bonded refractory castables.]

aumento de $0,48 \%$ na quantidade de partículas nanométricas de sílica, porém, a maior adição do ligante coloidal também proporciona um aumento no teor de água adicionada ao concreto. Assim, o aumento da porcentagem de partículas de sílica não foi eficiente na tentativa de melhorar a resistência à erosão devido ao fato de que um possível aumento da força de ligação da matriz é prejudicado pelo aumento da porosidade. Mas, como pode ser visto na Fig. 1, os valores de porosidade aparente foram similares e não foi possível correlacionar os resultados de volume erodido com esta propriedade. Mesmo para o produto comercial, onde a adição de água foi de $6,0 \%$, os resultados de porosidade aparente são semelhantes aos dos sistemas ligados por sílica coloidal, sendo ligeiramente superiores apenas para as temperaturas de queima de 1000 e $1200{ }^{\circ} \mathrm{C}$. Para os concretos contendo sílica coloidal e alumina hidratável como agente ligante, conforme mostra a Fig. 2, a formulação $(5 \% \mathrm{SC}+5 \% \mathrm{AH})$ apresentou superior desempenho para temperaturas inferiores a $800{ }^{\circ} \mathrm{C}$. Porém, para as temperaturas de 1000 e $1200{ }^{\circ} \mathrm{C}$ os resultados das duas formulações contendo sílica coloidal e alumina hidratável foram praticamente idênticos. Novamente, não é possível 
uma correlação entre a resistência à erosão e os resultados de porosidade aparente. Todas as formulações testadas, independentemente da combinação de sílica coloidal com alumina hidratável, apresentaram desempenho superior em relação ao produto comercial ligado por cimento de aluminato de cálcio. $\mathrm{O}$ benefício da maior sinterabilidade dos sistemas ligados por sílica coloidal pode ser verificado pelo baixo valor de volume erodido obtido mesmo para a temperatura de queima de $800{ }^{\circ} \mathrm{C}$. Em sistemas ligados por cimento aluminoso após a decomposição das fases hidratadas durante a etapa de secagem e queima em temperaturas intermediárias, o material só irá desenvolver uma ligação cerâmica para temperaturas de queima superiores a $1000{ }^{\circ} \mathrm{C}$. Como se verifica para o produto comercial, os resultados de volume erodido só são reduzidos para as temperaturas de queima de 1000 e $1200{ }^{\circ} \mathrm{C}$. A Fig. 3 apresenta os valores de resistência à erosão a frio das duas formulações de melhor desempenho para a faixa de temperaturas de queima entre 600 e $1500^{\circ} \mathrm{C}$.

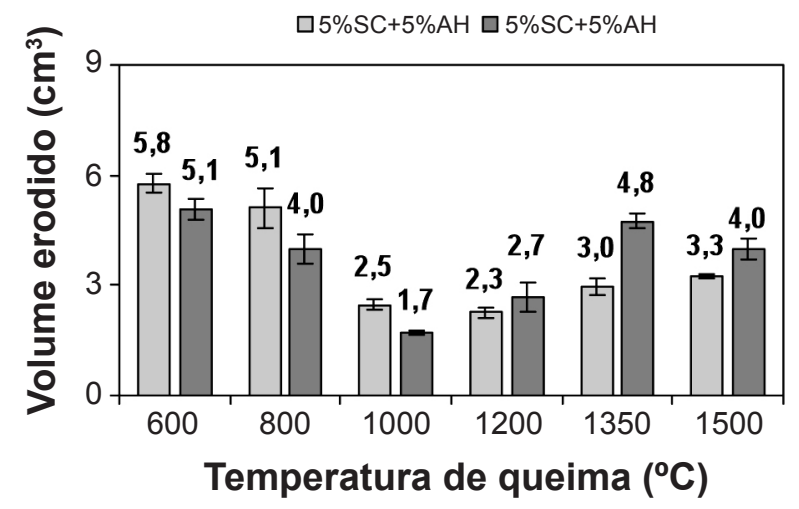

Figura 3: Resistência à erosão de concretos refratários contendo sílica coloidal como agente ligante.

[Figure 3: Erosion loss of refractory castables containing colloidal silica and a blend of colloidal silica and hydratable alumina as bonding agents.]

Os reduzidos níveis de volume erodido, inferiores a 6 $\mathrm{cm}^{3}$, para todas as temperaturas de queima evidenciam o bom desempenho dos sistemas ligados por sílica coloidal. Analisando o comportamento dos resultados em função da temperatura de queima, verifica-se uma redução do volume erodido para a faixa de temperaturas entre 600 e $1000{ }^{\circ} \mathrm{C} \mathrm{e}$ que para as temperaturas de queima de 1000 e $1200{ }^{\circ} \mathrm{C}$ os valores obtidos são inferiores a $3 \mathrm{~cm}^{3}$.

Comparação entre resistência à erosão a frio e módulo de ruptura a quente para os sistemas ligados por sílica coloidal

Os estudos do desgaste por erosão de materiais refratários tentam correlacionar a erosão com outras propriedades como a porosidade, resistência à compressão e módulo de ruptura à flexão. A melhor correlação obtida nestes estudos foi com a resistência à compressão diametral. Isto permite aos fabricantes uma rápida e fácil associação com a resistência à erosão sem a necessidade da condução de testes a frio ou a quente [11]. Na Fig. 4, são apresentados os resultados de resistência mecânica por compressão diametral para os sistemas ligados por sílica coloidal que apresentaram os melhores resultados nas etapas anteriores.

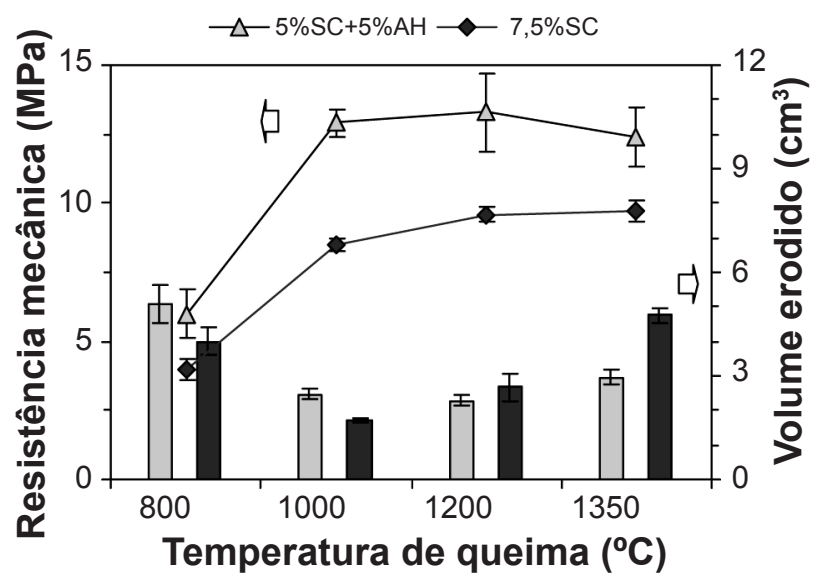

Figura 4: Comparação entre os resultados de resistência mecânica por compressão diametral e resistência à erosão a frio para os sistemas ligados por sílica coloidal.

[Figure 4: Correlation between cold mechanical strength and erosion loss as a function of firing temperature for the colloidal silica-containing refractory castables.]

A melhoria da resistência à erosão até a temperatura de queima de $1000{ }^{\circ} \mathrm{C}$ pode ser atribuída ao acréscimo da resistência mecânica a frio, porém, para as temperaturas de queima superiores a $1000{ }^{\circ} \mathrm{C}$ o aumento dos resultados de volume erodido não se relacionou a uma redução da resistência mecânica a frio. O que se pode afirmaré que a maior resistência mecânica apresentada pelo sistema $5 \% \mathrm{SC}+5 \% \mathrm{AH}$ pode ter contribuído para os seus menores valores de volume erodido em comparação ao sistema $7,5 \% \mathrm{SC}$ para as temperaturas de queima superiores a $1000{ }^{\circ} \mathrm{C}$.

Como os refratários são empregados em condições onde a resistência à erosão é também verificada a altas temperaturas, o módulo de ruptura a quente parece ser uma propriedade mais adequada para comparação. A Fig. 5 apresenta estes resultados para os sistemas ligados por sílica coloidal selecionados.

O comportamento do módulo de ruptura a quente foi similar para ambos os agentes ligantes, sendo que, a combinação entre sílica coloidal e alumina hidratável apresentou resultados ligeiramente inferiores. $\mathrm{O}$ aumento da resistência à erosão até a temperatura de queima de $1000{ }^{\circ} \mathrm{C}$, atribuída na Fig. 4 ao aumento da resistência mecânica a frio, também relacionou-se com o aumento do módulo de ruptura a quente. Com o seu decréscimo, para as temperaturas superiores a $1000{ }^{\circ} \mathrm{C}$, ocorreu o aumento dos resultados de volume erodido. Um comportamento similar foi verificado [9] onde formulações de concretos refratários contendo sílica coloidal que na temperatura de $1150{ }^{\circ} \mathrm{C}$ apresentavam valores de resistência mecânica na faixa de 25 a $30 \mathrm{MPa}$, na temperatura de $1300{ }^{\circ} \mathrm{C}$ tiveram sua resistência 


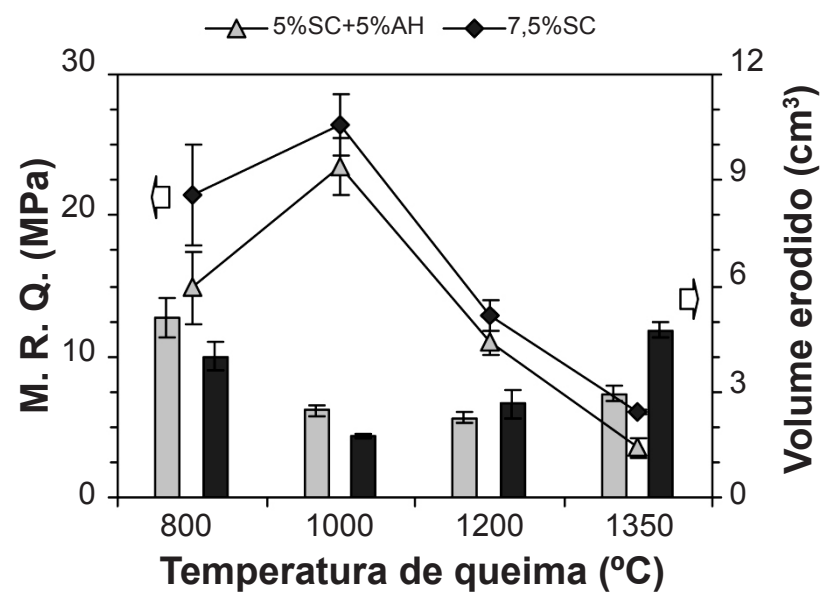

Figura 5: Comparação entre os resultados de módulo de ruptura a quente (M.R.Q.) e resistência à erosão a frio para os sistemas ligados por sílica coloidal.

[Figure 5: Correlation between hot modulus of rupture and erosion loss as a function of firing temperature for the colloidal silicacontaining refractory castables.]

mecânica reduzida consideravelmente, atingindo valores próximos a $14 \mathrm{MPa}$. Baseando-se na literatura [15], este fato foi associado à formação de uma fase líquida metaestável. Conforme mostra o trabalho [16] sobre o diagrama $\mathrm{Al}_{2} \mathrm{O}_{3}-$ $\mathrm{SiO}_{2}$, mesmo utilizando-se matérias-primas de alta pureza, a formação de uma fase metaestável de baixa viscosidade pode ser obtida em temperaturas próximas a $1260{ }^{\circ} \mathrm{C}$, reduzindo a resistência mecânica a quente. Os resultados da Fig. 5 indicam que o módulo de ruptura a quente pode ser relacionado com os resultados de resistência à erosão a frio na avaliação de materiais refratários. Como o teste de erosão é realizado a frio e a condição de uso do material é a quente, tal relação pode ser útil para a melhor seleção de produtos. Neste sentido, um parâmetro interessante seria a razão entre o módulo de ruptura e quente e o resultado de volume erodido (M.R.Q./V.E.). A Fig. 6 apresenta a comparação dos valores

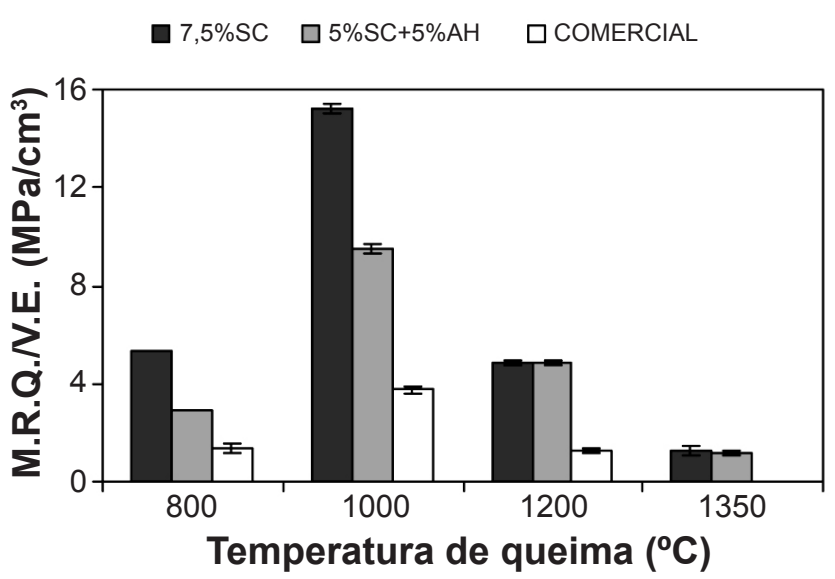

Figura 6: Comparação da razão entre módulo de ruptura a quente e volume erodido em função da temperatura de queima.

[Figure 6: Hot modulus of rupture:erosion loss ratio as a function of firing temperature.] desta razão em função da temperatura para as formulações de melhor desempenho, estudadas neste trabalho, em relação ao concreto refratário aluminoso de uso comercial.

$\mathrm{O}$ concreto refratário ligado por sílica coloidal, 7,5\% SC, apresentou o maior valor da razão entre o módulo de ruptura a quente e volume erodido, superando consideravelmente os demais sistemas à temperatura de $1000{ }^{\circ} \mathrm{C}$. Os resultados aqui apresentados mostram que a melhor faixa de aplicação dos sistemas ligados por sílica coloidal para solicitações de desgaste por erosão seria entre 800 e $1200^{\circ} \mathrm{C}$, o que os tornam adequados para a indústria petroquímica e em unidades integradas de fabricação de alumínio no revestimento dos equipamentos do processo de calcinação.

\section{CONCLUSÃO}

Os resultados de resistência à erosão a frio obtidos nesta avaliação preliminar de concretos refratários ligados por sílica coloidal mostraram que a utilização deste agente ligante no desenvolvimento de produtos para emprego em solicitações onde ocorre desgaste por erosão é muito promissora. Os melhores resultados foram obtidos para o sistema $7,5 \% \mathrm{SC}$, ligado somente por sílica coloidal, e para a combinação entre sílica coloidal e alumina hidratável $5 \% \mathrm{SC}+5 \% \mathrm{AH}$, sendo que, a melhor faixa de temperaturas para aplicação destes sistemas seria entre 800 e $1200{ }^{\circ} \mathrm{C}$. A análise do módulo de ruptura a quente e dos resultados de resistência à erosão a frio, mostrou que estas propriedades estão relacionadas. Assim, recomenda-se que a razão entre o módulo de ruptura a quente e o volume erodido seja um parâmetro apropriado para seleção de materiais refratários em aplicações onde a erosão e altas temperaturas são requeridas simultaneamente.

\section{AGRADECIMENTOS}

Os autores agradecem ao CNPq, à Petrobrás e à Alcoa Alumínio S.A. pelo apoio na realização deste trabalho.

\section{REFERÊNCIAS}

[1] S. Banerjee, Versatiliy of gel-bond castable/pumpable refractories, Refract. Appl. News 6, 1 (2001) 1-3.

[2] M. R. Ismael, F. T. Ramal Jr., V. C. Pandolfelli, Sol de sílica como agente ligante para concretos refratários, Cerâmica 52, 321 (2006) 82-87.

[3] M. R. Ismael, R. Salomão, V. C. Pandolfelli, Otimização do uso de sol de sílica como agente ligante para concretos refratários, Cerâmica 52, 321 (2006) 92-97.

[4] M. R. Ismael, R. D. Anjos, R. Salomão, V. C. Pandolfelli, Colloidal silica as a nanostructured binder for refractory castables, Refract. Appl. News 11, 4 (2006) 16-20.

[5] M. R. Ismael, R. Salomão, L. A. Polito, V. C. Pandolfelli, Agentes ligantes para concretos refratários: sílica coloidal e alumina hidratável, Cerâmica 53, 326 (2007) 142-146.

[6] R. Sarkar, S. Mukherjee, A. Ghosh, Gel-bonded aluminasilicon carbide-carbon-based blast-furnace trough castable, 
Am. Ceram. Soc. Bull. 85, 5 (2006) 9101-9107.

[7] A. R. Souri, B. Mirhadi, F. Kashani Nia, The effect of nano-structured colloidal silica on the properties of tabular alumina castables, Interceram 57, 6 (2008) 414-416.

[8]R.K. Iler,The chemistry of silica: solubity, polymerization, colloid and surface properties, and biochemistry, John Wiley \& Sons, New York, EUA (1979) p. 312.

[9] M. R. Ismael, F. A. O. Valenzuela, L. A. Polito, V. C. Pandolfelli, Propriedades termo-mecânicanicas de concretos refratários ligados por sílica coloidal, Cerâmica 53, 327 (2007) 314-318.

[10] S. K. Das, R. Sarkar, P. K. Mandal, S. Mukherjee, Nocement high-alumina self-flow castable, Am. Ceram. Soc. Bull. 82, 2 (2003) 55-59.

[11] S. Wiederhorn, Erosion of castable refractories, Refract. Appl. 2, 1 (1997) 2-6.

[12] V. A. A. dos Santos, F. A. O. Valenzuela, J. B. Gallo, V. C. Pandolfelli, Fundamentos e testes preliminares de resistência à erosão em concretos refratários, Cerâmica $\mathbf{5 2}$, 323 (2006) 128-135.

[13] I. R. Oliveira, A. R. Studart, R. G. Pileggi, V. C. Pandolfelli, Dispersão e empacotamento de partículas - princípios e aplicações em processamento cerâmico, Fazendo Arte Editorial, S. Paulo, Brasil (2000) p. 119.

[14] R. G. Pileggi, V. C. Pandolfelli, A. E. Paiva, J. Gallo, Novel rheometer for refractory castables, Am. Ceram. Soc. Bull. 79, 1 (2000) 54-58.

[15] M. V. Gerotto, R. G. Pileggi, V. C. Pandolfelli, Resistência mecânica a quente de concretos refratários aluminosos zero-cimento auto-escoantes contendo adições de microssílica e sílica coloidal, Cerâmica 46, 298 (2000) 91-96.

[16] S. H. Risbud, J. A. Pask, $\mathrm{SiO}_{2}-\mathrm{Al}_{2} \mathrm{O}_{3}$ metastable phase equilibrium diagram without mullite, J. Mater. Sci. 13 (1978) 2449-2454.

(Rec.07/07/2009, Ac. 20/12/2009) 